\title{
Trajetória acadêmica e pensamento sociológico: entrevista com Bernard Lahire*
}

\begin{abstract}
O sociólogo Bernard Lahire é professor da École Normale Supérieure Lettres et Sciences Humaines e Diretor do Grupo de Pesquisa sobre Socialização (CNRS / Universidade de Lyon 2). Sua obra mais conhecida no Brasil é o livro Sucesso escolar nos meio populares: as razões do improvável, publicado pela Ática em 1997. Essa entrevista foi concedida por e-mail a Maria da Graça Jacintho Setton, professora da Faculdade de Educação da USP, que também fez as notas explicativas e a revisão técnica da tradução.
\end{abstract}

Educação e Pesquisa: Parece interessante que o senhor nos conte sobre sua formação acadêmica e trajetória profissional, onde o senhor estudou, qual foi seu ponto de partida, quais são suas principais atividades e posição atual no meio universitário francês.

Bernard Lahire: Sou, como já disse, um produto puro da "universidade de massa". Sem dúvida, como você sabe, o sistema do ensino superior na França se distingue pela existência de um percurso nobre (classes preparatórias para as Grandes Écoles)' e um percurso escolar mais comum (universidade). Eu ingressei na universidade (a de Lyon 2) e aí construí o essencial de meus conhecimentos sociológicos.

0 ensino de sociologia em Lyon sempre foi marcado pela existência de uma pluralidade de escolas teóricas com as quais tive de me confrontar desde o início do curso. Nenhum dos grupos de professores - nem as diferentes categorias de marxistas, nem os bourdieusianos, nem os interacionistas, nem os foucaultianos, nem alguns dos tourainianos que lá estão... era maioria de fato na universidade. Na verdade, era um tanto desconcertante para os estudantes de sociologia, que ouviam discursos muito diferentes e contraditórios, mas penso hoje que foi uma sorte para mim ter sido obri- gado a viver permanentemente em dúvida sobre a pertinência das diferentes teorias sociológicas (que são ensinadas em outras universidades mais "monocromáticas", sob o espírito de catequese).

Proveniente de um ambiente popular, vindo de um dos bairros operários de Lyon, o estudo da sociologia agiu sobre mim como uma revelação. Cheguei à universidade com os questionamentos e as inquietações próprias à minha situação de trânsfuga de classe, e nela encontrei a sociologia, que começou a me trazer respostas satisfatórias. Rapidamente comecei a viver a sociologia como uma vocação e de forma apaixonada. Para mim não se tratava de uma simples formação acadêmica e de um simples percurso em busca de um diploma, mas de uma verdadeira experiência íntima, existencial, vital. Percorri todas as etapas sem saber muito bem aonde iria chegar (e, por vezes, sem saber exatamente o que viria depois), mas tinha a impressão de viver um privilégio enorme (e quase ilegítimo) ao passar meus dias (e por vezes também minhas noites) construindo meu olhar e minha profissão de sociólogo.

Essa dedicação inicial e freqüentemente considerada "irracional" só podia produzir efeitos bastante positivos na aquisição de conhecimentos. Sendo assim, percorri as diferentes etapas com relativa facilidade, sempre trabalhando intensamente, e em seguida tive a oportunidade de obter um posto de mestre de conferências (aos 29 anos) e, sobretudo, de professor universitário (aos 31 anos), bastante jovem. Fui

\footnotetext{
* Tradução do francês de Eugênio Vinci de Moraes e Maria A. C. Cappello. 1. Trata-se de um curso preparatório para o ingresso em uma seção particular do sistema de ensino francês, as "Grandes Escolas", estabelecimentos de ensino superior que preparam para as posições de poder do aparelho de Estado ou do setor privado. São instituições altamente seletivas, nas quais se ingressa mediante concurso. Entre elas podemos citar: Escola Central, Escola Politécnica, Escola Nacional de Administração, Escola de Altos Estudos Comerciais, Instituto Nacional Agronômico e as Escolas Normais Superiores.
} 
ainda beneficiado, entre 1995 e 2000, com excelentes condições de trabalho para realizar pesquisas no Instituto Universitário da França ${ }^{2}$ (um tipo de Collége de France ${ }^{3}$ descentralizado). E, finalmente, em 2000, fui admitido na Escola Normal Superior de Letras e Ciências Humanas, quando esse estabelecimento deixou a região parisiense para se estabelecer em lyon. É nesse espaço intelectual privilegiado (para o qual a seleção é particularmente severa) que eu ensino e pesquiso atualmente.

Em relação à sociologia havia ainda tudo a ser feito, uma vez que cheguei com a possibilidade de recrutar os colegas com os quais eu iria trabalhar. Sou o responsável pela sociologia desde o início. Montei ali também um laboratório ligado ao CNRS, ${ }^{4}$ intitulado Grupo de Pesquisa sobre a Socialização, que dirijo desde janeiro de 2003.

EP: Quais são os autores ou as escolas de pensamento que marcaram sua formação acadêmica? BL: Se eu interpretar sua questão em um sentido amplo e não apenas no sentido mais positivo, fui marcado, como já lhe disse anteriormente, por autores bastante diferentes e, em muitos casos, opostos. Freqüentei o curso de um dos tradutores franceses de Erving Goffman (antigo foulcaltiano convertido ao interacionismo), mas também os cursos de marxistas ortodoxos ou heterodoxos, como o de alunos diretos ou indiretos de Pierre Bourdieu. Mas os autores que mais me impressionaram foram, aleatoriamente, o lingüista e filósofo russo Mikhail Bakhtin, o lingüísta suiço Ferdinand de Saussure, o filósofo francês Michel Foucault, Maurice Merleau-Ponty (que foi professor de meu orientador de doutorado), o antropólogo inglês Jack Goody, o sociólogo e economista alemão Max Weber e, evidentemente, o sociólogo francês Pierre Bourdieu. Como eu me interessava muito pelas relações entre linguagem, pensamento e classes sociais, li também com bastante prazer autores como Benjamim Lee Whorf, Edward Sapir, William Labov, Basil Bernstein, John Gumperz tanto quanto os já citados anteriormente.
EP: Quais são os autores que lhe parecem mais importantes no que diz respeito à sociologia da cultura e da educação na França durante esses últimos anos? E por quê?

BL: A sociologia da educação e da cultura na França conheceu seus dias de glória nos anos de 1960-1970 com os trabalhos orientados por Pierre Bordieu e Jean-Claude Passeron. Desde os anos 1980 ela só vem perdendo influência (e interesse). A sociologia da cultura francesa está tão em baixa que, recentemente, para retomar a discussão sobre sociologia da cultura (em meu último livro intitulado $\mathrm{La}$ Culture des individus. Dissonances culturelles et distinction de soi ${ }^{5}$ ), precisei recorrer mais a trabalhos estrangeiros do que franceses. Autores norte-americanos como Paul Di Maggio ou Richard A. Peterson, como também os autores que publicam na excelente revista holandesa Poetics, Journal of Empirical Research on Culture, the Media and the Arts me inspiraram mais do que os sociólogos da cultura francesa em voga ou bastante influentes no meio acadêmico, que têm em mente apenas uma obsessão: fazer tudo para esquecer os trabalhos de Pierre Bourdieu. 0 problema é que em ciência (tanto nas ciências sociais quanto nas demais) não se pode desprezar o passado, sobretudo quando este foi tão fecundo.

EP: Como o senhor vê a influência atual da sociologia francesa no mundo? Onde o senhor situaria a vanguarda da sociologia moderna, se é que ela existe?

2. 0 Institut de France, criado em 1795, é um organismo altamente prestigiado no sistema de ensino francês e congrega várias instituições do ensino superior. Está diretamente ligado ao Ministério da Educação do país. 3. 0 Collège de France é uma instituição de ensino atípica. Está sob a responsabilidade do chefe de Estado, que delega sua tutela ao Ministério da Educação. Seus cursos não são ministrados de maneira convencional, ou seja, não sofrem nenhum tipo de regulação, inscrição ou avaliação. Mais informações podem ser encontradas em Almeida, A. O Collège de France e o sistema de ensino francês. In: Catanil, A. e Martinez, P. (Org.). Sete ensaios sobre o Collège de France. São Paulo: Cortez, 1999.

4. Centro Nacional de Pesquisa Científica, instituição de pesquisa vinculada ao Ministério da Educação francês, que congrega vários grupos de estudo e pesquisa, em parceria com professores do ensino superior ou pesquisadores autônomos.

5. La Culture des individus. Dissonances culturelles et distinction de soi. Paris: La Découverte, 2004 
BL: Questões espinhosas! Para falar da influência da sociologia francesa no mundo seria preferível consultar alguém que não fosse francês. Tenho uma convicção profunda (mas talvez eu seja muito otimista) de que quando uma sociologia é intrinsecamente poderosa (de um ponto de vista teórico e empírico) ela necessariamente vai além das fronteiras nacionais dentro das quais nasceu. Acredito que as coisas boas se difundem pelo boca a boca e graças aos pesquisadores mais puros que têm um amor real pelo trabalho científico bem feito.

Quanto à questão de saber onde eu situo a vanguarda da sociologia moderna, eu responderia, com o risco de parecer arrogante, que todo o meu esforço atual tende para o objetivo de representar esse pólo inovador. Como dizia Kuhn, "os inovadores eficazes" são aqueles que se apropriam da tradição (os "jogos" do passado) e que descobrem novas regras e novas peças de um jogo, com as quais podem continuar a jogar. Os sociólogos franceses são freqüentemente obnubilados pela oposição a Pierre Bourdieu e se esfalfam negando as contribuições desse autor, que, no entanto, permaneceu por vinte anos na vanguarda da sociologia francesa. Minha escolha foi sobretudo de afrontar essa sociologia, de me apropriar dela e de transformá-la do interior. No início tudo não passava de apresentar algumas nuanças, mas pouco a pouco cheguei a inventar algo como uma nova maneira de pensar o mundo social segundo uma escala individual, ou seja, levando sistematicamente em conta as variações inter-individuais e intra-individuais dos comportamentos. Minhas próprias interrogações são originárias da superação crítica (empírica e teórica) da teoria do habitus.

EP: 0 senhor poderia explicar as pequenas mas significativas transformações sofridas ultimamente por seus objetos de pesquisa? Inicialmente o senhor havia trabalhado no domínio da sociologia da educação, nos meios populares e, mais recentemente, o senhor se debruçou sobre a questão das práticas culturais dos fran- ceses. Que relações o senhor estabeleceria entre educação e cultura?

BL: Meus primeiros trabalhos referiam-se, com efeito, ao fracasso escolar de crianças de meios populares na escola primária, levando em conta a especificidade da cultura escrita escolar (Culture écrite et inégalités scolaires. Sociologie de l' "échec scolaire" à l'école primaire ${ }^{6}$ ). Sustentei a hipótese de que a origem das dificuldades estava diretamente ligada à natureza da cultura escolar e ao tipo de contribuição à linguagem (mais reflexiva, distanciada, meta-linguística) que a escrita tornou possivel. Posteriormente procurei observar aquilo que dizia respeito aos adultos dos meios populares, seus usos da escrita (seu modo de apropriação dos textos; suas práticas domésticas e profissionais da escrita) e descobri, nesse meio tempo, uma extraordinária divisão sexual das tarefas domésticas que envolviam a escrita: as mulheres dos meios populares escreviam muito mais que seus parceiros (La Raison des plus faibles. Rapport au travail, écritures domestiques et lectures en milieux populaires). ${ }^{7}$

A partir disso procurei encontrar casos improváveis de sucessos em meios populares para compreender as razões que fazem com que se tenha sucesso ali onde, estatisticamente, se deveria fracassar (Tableaux de familles. Heurs et malheurs scolaires en milieux populaires). ${ }^{8}$ Como eu trabalhava paralelamente no Observatório da Vida Estudantil, em Paris, também tomei por objeto as formas de estudar e as práticas culturais extra-escolares dos jovens que seguiam os estudos superiores (Les Manières d'étudier). ${ }^{9}$ Enfim, acabei por tomar como objeto os discursos públicos que tratam das dificuldades de escrever dos franceses, discursos que me parecem carregar verdadeiros fantasmas

6. Culture écrite et inégalités scolaires. Sociologie de l' "échec scolaire" à l'école primaire. Lyon: PUL, 1993.

7. La Raison des plus faibles. Rapport au travail, écritures domestiques et lectures en milieux populaires. Lille: Pul, 1993.

8. Tableaux de familles. Heurs et malheurs scolaires en milieux populaires. Paris : Gallimard/ Seuil, Hautes Études, 1995. Traduzido no Brasil como Sucesso Escolar nos meios populares: as razões do improvável. São Paulo: Atica, 1997.

9. Les Manières d'étudier. Paris: La Documentation Française, 1997. 
sociais sobre as "classes iletradas" considerandoas como novas classes perigosas (L'invention de $l$ ' "illetrisme". Rhétorique publique, éthique et stigmates). ${ }^{10}$

Direta ou indiretamente, meu trabalho sempre esteve no entrecruzamento de uma sociologia da educação e da cultura. Mais recentemente, no entanto, abri um grande campo de pesquisa sobre a relação dos franceses com a cultura legítima, que retomou a questão abordada por Pierre Bourdieu em La distinction, ${ }^{11}$ a saber, a da função social da cultura nas sociedades com divisão de classes. Mas, mesmo nesse último trabalho - La Culture das individus. Dissonances culturelles et distinction de soi - que claramente diz respeito à sociologia da cultura, encontra-se a marca dos efeitos do sistema escolar sobre os perfis culturais individuais. Não se pode trabalhar sobre os usos da cultura fazendo abstração da grande ligação existente nas sociedades fortemente escolarizadas entre capital escolar e práticas e preferências culturais. 0 volume e a natureza (literária versus científica) do capital escolar adquirido determinam em grande parte os gostos e disposições culturais.

EP: Sua crítica à teoria do habitus de Bourdieu parte do fato de que esse conceito não recobre a multiplicidade de referências identitárias vividas pelo homem contemporâneo. Considerando que esse conceito de habitus não pode ser dissociado de sua relação de interdependência com um campo social, como não vê-lo sendo construído a partir de uma nova arquitetura cultural? Acredito que esse conceito de habitus não pode ser interpretado unicamente como sinônimo de uma memória sedimentar e imutável; trata-se de um sistema de disposições continuamente construídas, abertas e sujeitas a novas experiências. 0 que o senhor pensa a esse respeito?

BL: Para ser mais preciso, eu não falo de "identidades múltiplas" ou de "referências identitárias", mas de pluralidade e de heterogeneidade de disposições incorporadas por cada agente nas sociedades com forte diferenciação social, nas quais a família não tem mais o monopólio da educação legítima das crianças. 0 argumento que eu desenvolvo em L'Homme pluriel'12 é que se definimos o habitus como um sistema homogêneo de disposições gerais, permanentes, sistemas transferíveis de uma situação à outra, de um domínio de práticas a outro, então cada vez menos agentes de nossas sociedades serão definíveis a partir de um tal conceito. Esse tipo de definição convém melhor para sociedades bastante homogêneas, demograficamente frágeis, com extensão geográfica relativamente pequena, que oferecem esquemas socializantes bastante estáveis e coerentes para seus membros. Nas sociedades em que as crianças conhecem muito cedo uma diversidade de contextos socializantes (a família, a babá ou a creche, a escola, os grupos de iguais, etc.) os patrimônios individuais de disposições raramente são muito coerentes e homogêneos. Bourdieu pensava que seria sobre a base de um habitus familiar bastante coerente já constituído que as experiências ulteriores adquiriam sentido. Os esquemas de socialização são de fato muito mais heterogêneos e cada vez mais precoces.

EP: Como o senhor interpreta o papel do sujeito social na teoria de Norbert Elias, notadamente no que diz respeito à relação de interdependência entre as instituições sociais e os individuos? Que proximidade e que distanciamento podem existir entre o conceito de habitus de Elias e de Bourdieu?

BL: Acredito que Bourdieu e Elias não tinham a mesma coisa em mente quando falavam de habitus. Em Norbert Elias, essa noção mantémse bastante fluida e geral (ele fala em habitus nacional). Bourdieu foi um dos que mais procurou definir esse conceito. Elias e Bourdieu pensavam os indivíduos como seres totalmen-

10. L'Invention de I' "illetrisme". Rhétorique publique, éthique et stigmates. Paris: La Découverte, 1999.

11. La distinction: critique sociale du jugement. Paris: Minuit, 1979.

12. L'Homme pluriel. Les ressorts de l'action. Paris: Nathan, 1998 Traduzido no Brasil como Homem plural: os determinantes da ação. Petrópolis: Vozes, 2002. 
te sociais, que são inteiramente socializados e cuja economia psíquica é fundamentalmente social, mas Elias nunca foi além de um uso superficial desse termo. Por seu lado, Bourdieu teorizou a noção, mas nunca trabalhou sobre a produção do habitus sobre a constituição de disposições constitutivas do habitus. Se o tivesse feito, ele teria se dado conta que uma parte de sua definição (e notadamente a questão da transferabilidade dos esquemas ou das disposições) não é evidente. Uma outra diferença entre a abordagem eliasiana e a abordagem bordieusiana, é o fato de que Elias apresenta como centro de sua sociologia a idéia de relações de interdependência entre indívíduos que formam então configurações sociais específicas e se constroem por meio dessas relações de interdependência. Bourdieu definiu os indivíduos sobretudo pelo volume e estrutura de seu capital (essencialmente o econômico e o cultural). Ainda que aparentadas, estas são duas concepções antropológicas definitivamente bastante diferentes.

EP: Nesses últimos anos, a sociologia moderna parece querer recuperar as contribuições de Georg Simmel. Ainda que de modos diferentes, François Dubet e Anthony Giddens se baseaim em Simmel para pensar uma sociologia do sujeito social. Ou seja, para discutir o papel ativo e reflexivo do indivíduo em relação às formações sociais modernas. 0 que o senhor diria sobre esses autores e suas contribuições à sociologia atual?

BL: 0 fato de buscar idéias em Simmel ou entre outros autores do passado ainda mais esquecidos do que ele me parece bastante natural. 0 que, no entanto, me parece suspeito é o uso "interessado" de autores do passado para fins atuais. Temos assim um Simmel (como também um Weber) recuperado segundo os adeptos do individualismo metodológico ou da teoria da ação racional, um Simmel para fenomenólogos sociais, etc. Eu mesmo pude jogar esse jogo ao mostrar que Simmel havia salientado a importância do pertencimento em vários círculos socias na formação de uma relação mais reflexiva (tendo a opção de comparar, os individuos ganham em liberdade mental com relação ao que se impõe como sendo totalmente natural, diferente dos que vivem dentro de um só círculo social). Mas acredito que, desse modo, fazemos os autores do passado dizerem coisas que eles não haviam dito; fazemos com que sustentem teses que não haviam sustentado, simplesmente porque procuramos fazê-los falar a nosso favor. Quanto aos dois autores sobre os quais a senhora me perguntou, eu diria que o primeiro é mais um teórico do social (o que em certa época chamávamos de "filósofo do social") do que um sociólogo que busca, por meio de pesquisas empíricas, encontrar a razão para determinados aspectos do mundo social, e que o segundo é um sociólogo que tem uma concepção pouco rigorosa, bastante jornalística da pesquisa empírica. A sociologia empírica é uma sociologia que deve ser impecável tanto no plano da construção teórica e da coerência da interpretação, quanto em relação à solidez e à pesquisa empírica. Aqueles que colocam em prática uma concepção pouco rigorosa da sociologia dão razão a todos que vêem nela apenas uma forma disfarçada de ideologia ou de jornalismo.

EP: A presença das mídias constitui uma reflexão "obrigatória” para aqueles que atualmente pensam a educação, notadamente para aqueles que se debruçam sobre os processos de socialização próprios ao mundo contemporâneo. 0 senhor acredita que as mídias podem ser consideradas como um novo "agente" de socialização? Por quê? Qual é a importância das mídias na França? Elas desempenham papéis equivalentes em países "desenvolvidos", como a França, e naqueles "em desenvolvimento", como o Brasil?

BL: As mídias como o rádio ou a televisão transformaram profundamente a relação que os individuos mantinham com a cultura e o lazer. É toda uma cultura do lar, doméstica (mais do 
que do que cultura de saídas ${ }^{13}$ ) que progressivamente se instalou. E também, de uma certa maneira, um poderoso meio de controle (certamente indireto e não intencional) das populações (basta ver o deserto em que se transformam as ruas das grandes cidades nas noites de grandes jogos de futebol televisionados). Levando-se em conta o tempo passado pelas crianças diante da televisão ou ouvindo o rádio, ninguém dúvida que isto modificou as condições de socialização infantil. Mas é difícil fazer das mídias agentes autônomos de socialização, uma vez que os efeitos das mídias são eles próprios mediatizados e filtrados pelos pais e pela escola: não se assiste da mesma forma à televisão em meios sociais diferentes, em função da situação escolar (boa ou má), etc. As mídias, portanto, só têm o poder que lhes damos: elas só exercem seu poder com a cumplicidade tácita dos adultos que permitem que se assista a elas ou que a elas assistem.

EP: Quais são as referências teóricas que lhe permitem pensar o papel das mídias em relação aos processos atuais de socialização?

BL: Eu mesmo nunca trabalhei diretamente sobre o papel das mídias audiovisuais nos processos de socialização. Mas acredito que uma boa sociologia dos usos sociais das mídias deverá se apoiar sobre as aquisições da sociologia da recepção (inspirada na sociologia da apropriação de Michel de Certeau, da estética da recepção de Hans R. Jauss ou da história cultural, cujo programa foi traçado pelo historiador da leitura Roger Chartier). Ela deverá lutar contra a idéia inicial de que as mensagens e as imagens se imprimem diretamente na mente das pessoas que assistem à televisão ou ao rádio. Trata-se de mostrar, levando-se em conta suas diferentes experiências sociais passadas, que as diferentes categorias de telespectadores ou ouvintes não tratam da mesma forma os programas que lhes damos para ver e ouvir. Os ouvintes ou telespectadores não se apropriam dos programas de maneira homogênea.
EP: Entre as diversas abordagens psicológicas, a psicologia histórico-cultural é notadamente a mais compatível com a sua orientação sociológica. Como o senhor poderia relacionar a questão da constituição da singularidade com a da gestão da heterogeneidade social explorada em seus trabalhos e, no plano psicológico, explorada por Vygotski e seus colaboradores?

BL: Eu já me sentia próximo de Vygotski antes mesmo de desenvolver a idéia de uma sociologia em escala individual e de me interessar pela questão das singularidades sociais. Vygotski estudou o papel da escrita e da escola no desenvolvimento da consciência metalingüística das crianças. É um autor que já está presente em La Reprodution ${ }^{14}$ de Pierre Bourdieu e Jean-Claude Passeron e que teve um papel fundamental no desenvolvimento de uma psicologia cultural nos Estados Unidos, notadamente mediante os trabalhos de Jérome Bruner. Atualmente, entretanto, em um país como a França, Vygotski conta muito pouco para uma comunidade de psicólogos que, em sua grande maioria, está convertida às ciências cognitivas e à idéia segundo a qual é preciso ser "experimental”, não ultrapassar os limites do laboratório e se aproximar das ciências duras (da neurobiologia e da imagética cerebral). Nesse contexto, a psicologia cultural e histórica só pode ser entendida como uma psicologia précientífica. Sendo assim, a sociologia que se interessa pela socialização dos indivíduos infelizmente encontra pouco apoio entre os psicólogos nos dias de hoje.

EP: Em seu livro Sucesso escolar nos meios populares, diferentes configurações familiares são exploradas de modo a esclarecer vantagens específicas e, ao mesmo tempo, permitir a construção de características gerais ligadas aos sucesso escolar. Como poderíamos aplicar essa mesma solução

13. Cultura de saídas é um conceito usado na literatura sobre lazer para se referir à prática de atividades culturais exercidas fora de casa.

14. Bourdieu, P. e Passeron, J.C. La Reproduction. Paris: Minuit, 1970. Publicado no Brasil com o nome de A Reprodução: elementos para uma teoria do sistema de ensino. Rio de Janeiro: Francisco Alves, 1982. 
metodológica ao contexto escolar, superando a idéia de escola como um meio social homogêneo? BL: Se quisermos considerar a escola em seus aspectos mais singulares, será necessário estudar as relações que se estabelecem entre alunos singulares e professores com características relativamente singulares (homens ou mulheres, jovens ou velhos, crianças de classe alta, média ou das classes populares, seguidores de determinada pedagogia, etc.), em contextos pedagógicos sempre singulares (estilo pedagógico da escola, características da população escolarizada, modo de inserção da escola no tecido urbano, etc.). Procurei destacar a diversidade de configurações familiares em meios populares que explica, em grande parte, as diferenças do destino escolar de crianças que, no entanto, têm capital familiar inicial bastante semelhante. Talvez seja necessário tentar descobrir, agora do lado da escola, a diversidade de situações e apontar para os contextos mais favoráveis ao sucesso escolar das crianças dos meios populares.

EP: Quais são as próximas questões nas quais o senhor pensa em trabalhar, seus projetos e planos de trabalho?

BL: Acabo de terminar um estudo sobre as práticas culturais dos franceses e estou trabalhando atualmente em dois grandes projetos. 0 primeiro diz respeito à construção social da personalidade cultural de crianças e adolescentes. Suas preferências e práticas, suas ações e reações tornam-se inacessíveis fora das relações sociais que se tecem entre eles e entre os membros da constelação social na qual eles se encontram. Com efeito, a criança, e poste- riormente o adolescente, constituem suas disposições mentais e comportamentais por meio das formas assumidas pelas relações de interdependência com as pessoas que, de modo mais frequente e durável, encontram-se ao seu redor. Ele não "reproduz" necessária e diretamente os modos de agir de seu entorno, mas encontra sua própria modalidade de comportamento em função da configuração na qual ele se vê inserido. Suas ações são reações que "se apóiam" de modo relacional nas ações dos diferentes agentes da constelação social que, sem o saber, circunscrevem, traçam espaços de comportamentos e representações possíveis para ele.

0 segundo projeto diz respeito ao estudo da vida literária, paraliterária e extraliterária dos escritores. A idéia geral dessa pesquisa é a de materializar os escritores, que muito freqüentemente são reduzidos a criadores "sem laços nem raízes" (aparentemente, o que pode haver de mais singular do que um "criador"?), em seres pensantes e em suas concepções de literatura, suas representações do que é para eles ser um “escritor”. Materializar os autores da literatura é reinscrevê-los nas condições de existência social e econômica (do que eles vivem?), nas redes de interdependências literárias, paraliterárias, e extraliterárias (com quem vivem e de quem dependem?) e nas condições materiais e temporais do trabalho da escrita (quando e como escrevem?). Um processo como esse se situa no cruzamento de uma sociologia das profissões (e a questão que nesse caso é particularmente instigante é a de saber em que medida a literatura pode ser encarada como uma "profissão", um "trabalho"), de uma sociologia dos processos de reconhecimento simbólico e de uma sociologia das práticas artísticas. 